\title{
Teachers as School-Based Mentors for At-Risk Students: A Qualitative Study
}

\author{
Francisco Simões $\cdot$ Madalena Alarcão
}

Published online: 27 August 2013

(C) Springer Science+Business Media New York 2013

\begin{abstract}
Background Over the past decade, administrators have implemented school-based mentoring (SBM) programs in schools across several western countries. However, few studies have compared the views of mentors and parents regarding the factors that determine SBM success.

Objectives The purpose of this work is to explore the factors that may facilitate or undermine the completion of SBM goals, according to the perspectives of both mentors and parents.

Methods We conducted a qualitative study using the focus group technique, followed by a content analysis. The study involved 22 mentors and 16 parents. We then classified the emergent themes as either facilitators of or barriers to SBM success.

Results and Conclusions The participants focused on how the relationships of mentors with parents, teachers and, more rarely, with social service officials affected the SBM accomplishments. The participants seldom regarded the characteristics of the mentees as an important influence on mentoring effectiveness. Our findings suggest that mentoring delivered by teachers may help to address some of the practical limitations of SBM programs. However, the overlap of mentoring and teaching roles in SBM may also necessitate additional care regarding the definition of purposeful interactions of the mentors with the other adults who are significant in the lives of the mentees, namely their parents and teachers.
\end{abstract}

Keywords School-based mentoring $\cdot$ Mentors $\cdot$ Parents $\cdot$ Teachers

F. Simões $(\bowtie) \cdot$ M. Alarcão

Faculty of Psychology and Educational Sciences, University of Coimbra, Rua do Colégio Novo,

3000-802 Coimbra, Portugal

e-mail: francisco.simoes@cipp-terceira.com 


\section{Introduction}

Over the past decade, mentoring has become extremely popular. Its growth relies on the premise that young people who have experienced adversities in their lives may find in mentoring an opportunity to readjust their internal working models and compensate for losses in previous relationships with adults (Rhodes 2002; Russell 2007). Consequently, promoters often present mentoring to the general public as a straightforward means of fulfilling the needs of the mentees. However, research has shown that several factors may help or undermine the effectiveness of mentoring. In the specific case of school-based mentoring (SBM), one can organize the facilitators and barriers of mentoring effectiveness along three dimensions: relational factors, the individual characteristics of the mentors and mentees and the implementation features of the programs.

School-based mentoring tends to deliver better outcomes when the mentoring relationships are longer (Grossman et al. 2012) and the mentor-mentee contacts are frequent and consistent (Deutsch and Spencer 2009). Mentoring is also more effective when the mentors cooperate with the other adults who are significant in the lives of the mentees. For example, parents may positively affect mentoring outcomes when they cooperate with or coach mentors, particularly when the mentors are young and are not parents themselves (Spencer et al. 2011). Parental relationship quality may also mediate the association between mentoring relationships and youth outcomes (Chan et al. 2013; Spencer et al. 2011). However, opinions diverge regarding how to manage the communication between mentors and other significant adults, such as parents. Some experts urge agencies to invest in raising the quality of the interactions between parents and mentors (Keller 2005), while others are more skeptical, arguing that the parental involvement in mentoring should be minimal to avoid negative influences (Miller 2007).

The individual characteristics of the mentors and mentees may also influence the success of SBM relationships. SBM generally delivers better outcomes when the mentors are older (Grossman et al. 2012), have a background in educational or caregiver roles (DuBois et al. 2002) and feel confident in their ability to cope with vulnerable youth (Karcher et al. 2005). In turn, the gender and age of the mentees are also influential factors on the effect of SBM: younger boys and older girls benefit more from having a school mentor (Karcher 2008). In addition, high levels of individual and environmental risk seem to be counterproductive to mentoring effectiveness (DuBois et al. 2011), whereas other findings support the conclusion that both low and high levels of relational risk negatively influence academic outcomes, such as school grades, in SBM (Schwartz et al. 2011).

Finally, a number of studies have depicted how the implementations of SBM programs predict their success. Systematic reviews have demonstrated that the models used to implement SBM programs are tremendously diverse (Wheeler et al. 2010). Nevertheless, programs that are based on purposeful and planned activities developed during SBM sessions (Karcher 2008) are generally more effective. In addition, those programs which do not involve removing the mentees from their classes (Schwartz et al. 2012) and which duly organize the training and supervision of the mentors (Komosa-Hawkins 2009) and the mentor-mentee matching (Karcher et al. 2005) tend to have a more positive impact as well.

Despite the remarkable progress in the SBM research field, there are two obvious limitations in the literature. First, the studies usually compare the perceptions of the mentors with those of the mentees to determine the effectiveness of SBM (Herrera et al. 2011), without considering the perspectives of the other significant adults regarding the underlying factors that lead to better or worse mentoring outcomes. Second, the previous studies have focused on SBM delivered by volunteer mentors who are external to the 
school staff and these individuals usually have little or no background in educational roles (DuBois et al. 2011). Therefore, our overriding aim is to explore the perspectives of the mentors and parents regarding the facilitators and barriers to effective mentoring in a Portuguese SBM program called Metodologia TUTAL. A unique feature of this SBM program contextualizes this exploration; the mentors are also the teachers of the mentees. We believe that allowing an overlap between mentoring and teaching may lead to a more detailed description of the relational factors that underscore the SBM experience within the framework of the intricate process of communication between mentors, parents and teachers.

\section{Teachers as Mentors}

Mentoring and teaching share some common features. Both are dyadic relationships in which the adult may assist the mentee to achieve goals related to school learning, based on his or her knowledge or experience (Goldner and Mayseless 2008). However, only approximately one-quarter of school mentors reported spending the majority of the mentoring time completing homework or studying with the mentees, regardless of whether they were also the mentees' teachers (Herrera et al. 2007). Although SBM is more successful at improving the academic performance of the mentees than, for example, natural or community-based mentoring programs (DuBois et al. 2011), these results might also reflect the fact that mentors help their mentees develop a wider range of competencies, such as personal and social skills. Moreover, different mentees may require different approaches: older and male mentees seem to require more dedication from their mentors toward instrumental goals, such as mastering a task or a trade or academic guidance, compared to younger and female mentees (Karcher 2008; Spencer 2006).

The formal educational background of the teachers might have important implications for SBM programs (DuBois et al. 2002). Mentors who are also teachers may help mentoring programs bridge the gap between an informal authority that they share with the parents, based on proximity, and a legal authority granted to formal social relationships (Goldner and Mayseless 2008). The ability to alternate between formal and informal approaches may be crucial to increase the degree to which the mentees endorse the norms of the school. In addition, the option to place teachers in the mentoring role may help address the practical drawbacks of SBM programs. If teachers are also mentors, schools can more easily organize pre-matching activities at the beginning of the school year and avoid short matches or premature termination of SBM relationships (Chan and Ho 2008; Grossman et al. 2012). Teacher mentors can also schedule SBM meetings in advance to avoid removing the mentees from their classes (Schwartz et al. 2012), which is not always possible when the mentors are volunteers coming from the community (Karcher 2008).

The choice to select teachers to mentor their students might also have limitations. SBM delivered by teachers can replicate or even intensify the tensions and conflicts involved in school-family relationships. Mentors may expect a high degree of behavioral, affective and cognitive involvement from the parents in their children's school lives; mentors may specifically anticipate that SBM will make parents more willing to care about their children's achievements and provide additional learning opportunities at home (Grolnick and Slowiaczek 1994). In turn, parents may not notice the differences between mentors and other teachers, leading them to interpret their relationships with mentors as bureaucratic or professional rather than informal, as intended in SBM (Addi-Racah and Ainhoren 2009; Epstein 2001; Omer 2011). 


\section{Metodologia TUTAL}

Metodologia TUTAL is a Portuguese SBM program developed between 2007 and 2009 by a consortium of public and private organizations, under a grant from the European Social Fund (EQUAL Communitarian Initiative). The program resulted from a project organized in one school involving 64 mentees enrolled in basic education (grades 7-9). In 2010 and 2011, the program spread further. Our work refers to this later phase.

In 2010-2011, 157 mentees were involved in Metodologia TUTAL. They were all Portuguese students referred to the program by the school boards because of low school attendance rates, an indication for supplementary classes, disciplinary problems and/or underachievement. The mentored students showed the following characteristics: aged 9-16 years old $(M=12.75, \mathrm{SD}=1.75)$; enrolled at the basic education level (5th to 8th grade) at six schools that taught 5 th to 12 th grade; $57.3 \%$ female; and $80.3 \%$ were supported by the social services of their schools, meaning that they came from lower income families.

The mentors were teachers who volunteered to mentor their own students. Whenever the number of volunteer teachers failed to meet the needs of the program, the school boards invited other teachers to participate. Both the volunteer and invited teachers had to meet two selection criteria: (a) they must have had some experience in informal mentoring in school or in the community and (b) preferably, they should be members of the permanent staff of their respective school. The mentors enrolled in a 16-h training program prior to the beginning of the official school year. The training included: (a) basic information about SBM and the main features of Metodologia TUTAL; (b) practicing communication and motivational skills to work with the mentees and their families; and (c) planning activities in the context of group and one-on-one mentoring sessions. Ongoing supervision of the program comprised monthly meetings and informal contacts by phone and e-mail with a coordinator from a non-governmental organization responsible for promoting the program. The mentors did not receive any compensation for participating in the training program and in monthly supervision meetings.

The mentoring lasted approximately 9 months, and the activities occurred in two formats. Ninety-minute weekly group mentoring sessions promoted by the mentors started at the beginning of the school-year; the sessions focused on the schoolwork orientation of the mentees and promoted their social integration and the discussion of themes that were relevant to each group. The group mentoring sessions preceded one-on-one sessions to facilitate mentor-mentee matching. One month later, the mentees and mentors started exploratory one-on-one discussions on their goals for the mentoring relationship. These discussions adapted into a process of negotiation between the involved parties and paved the way for the dyadic mentoring relationships that were established 2 weeks later, according to shared goals and mutual interests. Weekly one-on-one SBM meetings occurred during the school day and lasted an average of $30 \mathrm{~min}$. The meetings were planned according to the mentor and the mentee weekly schedule and did not involve removing the mentees from their classes. The activities during the sessions focused on satisfying the basic psychological needs of the mentees (Ryan and Deci 2000) by assisting them with the following goals: (a) completing academic-related tasks, such as homework or studying; (b) addressing stressful or positive relationships with peers, teachers or parents, in a context dominated by relational interest, closeness, and trust; (c) providing feedback, discussion or role-modeling of self-regulation strategies for multiple issues, such as school attendance, or providing information that could assist in important decisions, such as choosing future learning programs. The one-on-one mentoring also included 
informal activities, consisting of interactions promoted by the mentors outside of the classroom or office. Mentors could regulate their support to the different needs of their mentees and accordingly choose the activities for development with the mentees during the SBM sessions.

Parents were informed regarding the program, and their consent for the participation of their children was obtained. At the beginning of the school year, the mentors met with parents and teachers to discuss the SBM goals and activities. Informal meetings between mentors and parents took place while the program was underway. The mentors and teachers met during regular teacher meetings scheduled throughout the school year.

\section{The Current Study}

The purpose of this work is to explore the factors that influenced mentoring outcomes in the Metodologia TUTAL program. This aim relies on one central research question: which factors exerted a positive or negative influence on achieving the SBM goals? The focus on identifying potential facilitators of and barriers to the effectiveness of this program stems from the need to determine research-based practices in the field of mentoring (DuBois et al. 2011). This need is further justified by the unusual combination of teaching and mentoring roles in the Metodologia TUTAL, and the general demand for more comparisons between the views of mentors and parents in the SBM field (Spencer et al. 2011).

We implemented a qualitative study to accomplish our aim, involving the mentors and the parents of the mentees. Our intention was to triangulate the perspectives of different key actors about the effectiveness of the Metodologia TUTAL in order to identify the (in)consistencies across different informers and, therefore, to establish the impact of SBM more accurately (Bryman 2006). Data collection was based on the focus group technique and using a subsequent content analysis. Experts recommend the focus group technique to study various mentoring topics, such as perceived satisfaction with the program, or to explore the factors that influence mentoring relational processes (Deutsch and Spencer 2009). In addition, our aim was to discover barriers to and facilitators of SBM interventions with different informers. The focus group technique is appropriate for achieving this specific goal, as it enables us to explore consensus or the lack of it in a context that maximizes real-world responses due to the realism of social interactions, as opposed to other qualitative data collection techniques (e.g. interviews) (Krueger and Casey 2008).

\section{Methods}

The research protocol and data collection procedures were based on a proposal by Vicsek (2010) of the factors that determine the course of focus groups. This proposal is grounded on the constructivist assumption that we can only estimate individual attitudes by considering the social context in which they occur. In the case of a focus group, one can interpret the meaning more precisely if the contributions of the different participants are considered instead of isolated opinions.

According to Vicsek (2010), the nature and content of focus group discussions are influenced by individual, interactional and situational factors. Individual factors include the participants' and moderator's characteristics such as gender, age, social status or professional experience. Interactional factors refer to the exchanges between the participants and how consensus or divergences stem from the discussions. Specifically, the opinions held by 
the participants may reveal processes of social conformism to the group, which can be influenced by a minority of or alliances between participants (Eagly and Chaiken 1993). Situational factors refer to the environment (the place where the discussions take place), time (duration of the discussions) and content of the discussions (relational atmosphere, communication of the research goals and type of questions).

The influence of individual factors can be better understood if the main characteristics of the participants and moderator are properly described. The management of interactional factors is related to the organization of the groups, namely how much homogeneity or heterogeneity between the participants is wanted and/or achieved by the researcher, the presentation of quotes that reflect the exchanges between the participants and the description of communication elements (e.g., laughter or changes of intonation) that add meaning to the interactions. The consideration of situational factors involves promoting an adequate atmosphere for the discussions or the preparation of questions and prompts. Throughout this section, we provide descriptions of each of these categories of variables and of how they were treated to ensure trustworthiness and credibility.

Individual Factors

\section{Participants}

We invited all the 36 mentors who delivered SBM in the six schools that implemented Metodologia TUTAL to participate in this study. All of the mentors agreed to participate, but only 22 mentors $(61.1 \%)$ from five different schools participated in the focus groups. The remaining 13 mentors were unable to attend because of scheduling conflicts. The 22 mentors who participated were Portuguese native speakers. As described in Table 1, 16 of the mentors were female; their ages ranged from 31 to 54 years old $(M=39.52$, $\mathrm{SD}=5.95)$; and 19 belonged to the permanent staff of their respective school. Their teaching experience ranged from 7 to 35 years $(M=14.17, \mathrm{SD}=6.39)$.

In the case of the parents, we randomly selected 24 of them from the 157 legal representatives of all of the students mentored in the Metodologia TUTAL program during the 2010-2011 school year. Then, we selected a proportionate number of parents of male and female mentees (12 each). Six parents were unavailable due to scheduling conflicts and two declined the invitation. Sixteen parents agreed to participate. They were all Portuguese native speakers. As described in Table 2, of the 16 parents who agreed to participate in the research, 15 were mothers. Their ages ranged from 32 to 57 years old $(M=45.00$, $\mathrm{SD}=8.17)$. Fifteen were the biological parents of the mentees, and one was an adoptive

Table 1 Mentor demographic information by focus group

\begin{tabular}{llllc}
\hline Groups & $\begin{array}{l}\text { Gender } \\
\text { M (F) }\end{array}$ & $\begin{array}{l}\text { Age } \\
\text { M (SD) }\end{array}$ & $\begin{array}{l}\text { Experience in years } \\
\text { M (SD) }\end{array}$ & $\begin{array}{l}\text { Professional status } \\
\text { Permanent (recruited) }\end{array}$ \\
\hline Focus group 1 & $2(4)$ & $37.50(5.32)$ & $12.83(6.82)$ & $3(3)$ \\
Focus group 2 & $1(5)$ & $38.67(3.83)$ & $13.00(2.90)$ & $6(0)$ \\
Focus group 3 & $0(5)$ & $41.17(6.71)$ & $12.67(2.73)$ & $6(0)$ \\
Focus group 4 & $3(2)$ & $41.00(8.43)$ & $19.00(10.44)$ & $5(1)$ \\
Total & $6(16)$ & $39.52(5.95)$ & $14.17(6.39)$ & $19(4)$ \\
\hline
\end{tabular}


Table 2 Parent demographic information by focus group

\begin{tabular}{lcll}
\hline Groups & $\begin{array}{l}\text { Gender } \\
\text { F (M) }\end{array}$ & $\begin{array}{l}\text { Age } \\
\text { M (SD) }\end{array}$ & $\begin{array}{l}\text { Professional status } \\
\text { Employed (unemployed) }\end{array}$ \\
\hline Focus group 1 & $4(0)$ & $47.00(9.84)$ & $3(1)$ \\
Focus group 2 & $4(0)$ & $56.00(1.41)$ & $3(1)$ \\
Focus group 3 & $3(1)$ & $42.33(1.15)$ & $3(1)$ \\
Focus group 4 & $4(0)$ & $38.33(5.51)$ & $3(1)$ \\
Total & $15(1)$ & $37.52(5.44)$ & $12(4)$ \\
\hline
\end{tabular}

mother. Nine of the parents were the legal representatives of boys. The educational level of the parents ranged from 4th to 9th grade, and twelve of them had a permanent job.

\section{Moderator}

The moderator of the eight focus groups was one of the authors. He was 32 years old and his first language is Portuguese. He was chosen, because he had prior experience of moderating focus groups. In addition, he had become familiar with the schools that implemented Metodologia TUTAL as he worked for the organization responsible for running the program.

\section{Interactional Factors}

Two interactional factors likely influenced the focus groups held with the mentors and parents. First, the mentors of each group knew one another; they underwent shared training sessions prior to the implementation of the program. Second, the level of prior interaction depended on whether the participants worked together, in the case of the mentors, or were legal representatives of the children attending classes at an identical school, in the case of the parents. To control for the influence of this familiarity, each group included participants from at least two different schools. In addition, we organized all of the groups in order to balance the homogeneity and heterogeneity of the participants' characteristics in each group.

The mentors participated in four focus groups, comprising five to six participants each.

The groups were homogeneous in that all of the participants were mentors and teachers and the average experience level was similar (except for Focus Group 4). In most of the groups, we managed to gather mentors who were members of the permanent staff of their respective schools, with the exception of Focus Group 1. We also managed to gather groups with similar average ages. By the contrary, we intentionally manipulated heterogeneity within the groups with regard to gender: all the groups included both males and females, with the exception of Focus Group 3.

In the case of the parents, each focus group comprised four participants. The groups were arranged in order to ensure homogeneity with respect to gender (15 out of 16 participants were female) and the fact that all of the parents were legal representatives of the mentees at school. The groups were heterogeneous regarding the professional backgrounds of the participants (nine of them were housekeepers, two worked in healthcare services, one had a small business and the remaining four were unemployed) and the average age of each group, but these were unintended features.

Neither the mentors nor the parents received incentives to participate in this study. 


\section{Situational Factors}

\section{Environment and Time}

With respect to the environment, our intention was to organize all of the discussions in the same place. Two of the focus groups for the mentors and all of the focus groups for the parents occurred at one of the non-governmental organizations responsible for running the program. The remaining two discussions for the mentors took place at one of the schools that implemented Metodologia TUTAL.

The focus group discussions took place 1-3 months after the program was concluded. The focus groups with mentors occurred first and lasted an average of $1 \mathrm{~h}$ and $39 \mathrm{~min}$, ranging from $1 \mathrm{~h}$ and $18 \mathrm{~min}$ (Focus Group 3 ) to $2 \mathrm{~h}$ and $3 \mathrm{~min}$ (Focus Group 4). The focus group discussions with parents lasted an average of $47 \mathrm{~min}$, ranging from $45 \mathrm{~min}$ (Focus Group 2) to $48 \mathrm{~min}$ (Focus Group 3).

\section{Discussion Content}

We organized the focus groups according to three stages: preparation, discussion and conclusion. In the preparation stage, the moderator greeted the participants in the room where the discussion occurred. Purposeful small talk occurred for approximately $15 \mathrm{~min}$ while soft drinks and appetizers were served to create a relaxed and informal atmosphere before the discussion. The discussion began with a presentation of the general goal and discussion rules for the meeting. The moderator then introduced four open-ended research questions, one at a time. We explored two topics: the general outcomes delivered by the SBM program and the barriers or facilitators that might have influenced mentoring. The current report focuses on the latter topic. The groups explored the questions using a script prepared by the authors. Table 3 shows the discussion topics, research questions and examples of the prompt questions. Flexibility was an important component of the discussion process; therefore, the moderator chose the question prompts according to the answers of the participants. To conclude, the moderator delivered a summary and asked the participants to provide feedback so that possible biases of the moderator could be avoided and each group could validate the main conclusions included in the summary.

Table 3 A summary of discussion topics, questions, and prompt question examples

\begin{tabular}{|c|c|c|}
\hline $\begin{array}{l}\text { Discussion } \\
\text { topic }\end{array}$ & Questions & Prompt questions examples \\
\hline $\begin{array}{l}\text { SBM barriers } \\
\text { and } \\
\text { facilitators }\end{array}$ & $\begin{array}{l}\text { In your opinion, what were the barriers to } \\
\text { successful SBM relationships? } \\
\text { In your opinion, what were the factors that } \\
\text { facilitated successful SBM } \\
\text { relationships? }\end{array}$ & $\begin{array}{l}\text { Could you explain to me how the mentors } \\
\text { were a facilitator/an obstacle to better SBM } \\
\text { outcomes? } \\
\text { Could you explain to me how the parents } \\
\text { were a facilitator/an obstacle to better SBM } \\
\text { outcomes? } \\
\text { Could you explain to me how the other } \\
\text { teachers were a facilitator/an obstacle to } \\
\text { better SBM outcomes? } \\
\text { Could you explain to me how cooperation } \\
\text { with community services was a facilitator/ } \\
\text { an obstacle to better SBM outcomes? }\end{array}$ \\
\hline
\end{tabular}


We video recorded and transcribed all of the focus groups and then verified all of the transcriptions. The transcription process included a consideration of verbal and non-verbal communication elements, as well as other speech elements (e.g., overlaps, pauses, a tone of voice that conveyed emphasis [in upper case letters] and laughter) and gestures.

We performed separate content analyses for the mentor and parent discussions, using NVivo 8, a software program that supports qualitative and mixed methods research. We considered the theme as the coding source in a five steps process of content analyses.

The first step involved codifying all of the excerpts of the discussions into one of two predetermined themes: facilitators of or barriers to the success of SBM. The second step involved codifying the excerpts again into emergent subthemes according to their common elements. The emergent subthemes considered certain principles, such as homogeneity (all the data were collected using identical methodology), mutual exclusion (each quotation was codified under a sole theme and subtheme), relevance (the data analyzed pertained only to the subject under study), and objectivity (the quotations reflected the definition of each theme and subtheme) (Bardin 2004). Thirdly, we combined the initial subthemes that were less frequent into the same subtheme. Our revision stemmed from the fact that some of these infrequent subthemes reflected different nuances of the same subtheme.

Fourthly, after one of the authors conducted an initial full-content analysis, we calculated the inter-coder agreement separately for all of the data provided by the mentors and parents. The process involved three coders: the author and two additional coders. This step was based on the codes established by the first coder. The inter-coder agreement process was progressive. The two coders received feedback and written guidelines from the author regarding the meaning of the themes. The coders then met with the author who conducted the initial content analysis to codify some of the quotations and ensure a common understanding of each theme. Subsequently, the two additional coders classified all of the transcribed data, and we compared their results to calculate the paired inter-coder agreement between the two coders and between the coders and the author. The inter-coders also helped to codify seven excerpts which did not readily reflect either a barrier or a facilitator. These excerpts involved the participants' divergent opinions about a particular topic. The author and the coders analyzed each of these excerpts and agreed to codify it according to the opinion that was shared by most of the participants in the discussion. The level of intercoder agreement was adequate for the content analysis of the data provided by both the mentors (ranging from $k=.79$ for coders 2 and 3 to $k=.87$ for coders 1 and 2) and parents (ranging from $k=.88$ for coders 1 and 2 and coders 2 and 3 to $k=.95$ for coders 1 and 3).

Finally, we organized the data according to the number of focus groups and participants in each focus group who referred to a particular subtheme.

\section{Results}

In the next subsections, we present the subthemes that emerged from the discussions with the mentors, followed by the subthemes that resulted from the discussions with the parents for each of the preexisting themes (facilitators of and barriers to SBM). Tables 4 and 5 summarize the results for both the mentor and parent groups respectively. Throughout this section, we refer to the participants using pseudonyms. All the quotes presented below were translated. 
Table 4 Results of the content analysis conducted on the data provided by the mentors $(n=23)$

a The number of references to a particular subtheme

b The number of groups in which the subtheme was identified

c The number of participants (mentors) that referred to this subtheme

Table 5 Results of the content analysis conducted on the data provided by the parents $(n=16)$

a The number of references to a particular subtheme

b The number of groups in which the subtheme was identified

c The number of participants (parents) that referred to this subtheme

\begin{tabular}{lrrr}
\hline Mentors & & & \\
\hline Themes and subthemes & $\mathrm{a}$ & $\mathrm{b}$ & $\mathrm{c}$ \\
\hline Barriers & & & \\
Parental involvement & 27 & 4 & 13 \\
Other teachers & 10 & 4 & 8 \\
Community & 4 & 2 & 5 \\
Time & 3 & 2 & 3 \\
Facilitators & & & 5 \\
Innovative organization & 11 & 4 & 10 \\
Other teachers & 10 & 4 & 5 \\
Parental involvement & 7 & 3 & 2 \\
Community & 2 & 2 &
\end{tabular}

Parents

\begin{tabular}{lrcc}
\hline Themes and subthemes & $\mathrm{a}$ & $\mathrm{b}$ & $\mathrm{c}$ \\
\hline Facilitators & & & \\
Mentoring relationship & 16 & 4 & 7 \\
Communication parents/mentors & 13 & 4 & 6 \\
Parental involvement & 6 & 3 & 4 \\
Other teachers & 6 & 3 & 5 \\
Barriers & 14 & 4 & 8 \\
Communication parents/mentors & 11 & 3 & 4 \\
Other teachers & 6 & 4 & 5 \\
The mentees' characteristics & 3 & 2 & 2 \\
Schools & & & \\
\end{tabular}

\section{Barriers to SBM Identified by the Mentors}

The content analysis of the data provided by the mentors presented in Table 4 revealed that they more frequently identified Barriers (44 references) to SBM success. This theme covered the statements by the mentors recognizing the factors that negatively influenced SBM success. The most frequently mentioned barrier to successful SBM relationships was the absence of Parental Involvement (27 references). This subtheme encompassed the mentor accounts of how the parents indirectly undermined their children's school achievement, which was also the main goal of SBM. Often (20 references), the absence of parental involvement was described as the lack of parental incentive for involvement with their children's studies or a weak definition of rules in relation to school issues at home. Occasionally, the absence of parental involvement stemmed from dysfunctional family relationships, under-emphasis of schooling at home or negative parental expectations regarding their children's school achievement. The absence of parental involvement in $\mathrm{SBM}$, in terms of lack of incentive and negative expectations, is illustrated by the following discussion in Focus Group 1. 
Cidália: (...) I also think that many of the kids did not improve because, at home, parents do not value school.

António: But...yes, that is also true.

Cidália: For instance, when Carolina was doing her homework, her brothers mocked her and said, "You're stupid. You can't do this or you can't do that." This means that even their family, their parents demoralize them... (...).

António: Yes, I agree with you on that point.

The mentors described negative relationships between the mentees and Other Teachers (10 references) as a negative influence on SBM success as well. They referred to negative relationships between the mentees and other teachers in terms of the absence of opportunities for the mentees to participate in class, the inability to motivate these students or, more often, as an inflexibility regarding the requirements of the mentees, as the following disciplinary situation reported in Focus Group 1 illustrates.

António: (...) We've been talking about the mentee's responsibility and the parent's responsibility, but some teachers also have a responsibility in this issue (the effectiveness of SBM)! We are delivering a mentoring program. We must motivate our mentees.

Rosa: Regarding this issue, it's important to note that some [of the mentees] were excluded due to disciplinary problems because they were systematically expelled from classes.

António: Precisely (nods his head affirmatively).

Rosa: This was a huge problem, especially with one teacher.

Cidália: (...) That was a problem for me too. Once, I saw a mentee outside the classroom by the door, and I asked him, "Why are you here?" and he said, "Because I don't want to go in". And then I convinced him to go in (...) but the teacher said, "YES, but he already has an absence." This was an invitation for the student to leave (...).

The mentors sometimes viewed the Community Stakeholders (4 references) as an obstacle to SBM. This subtheme included the accounts by the mentors of how cooperation with community services officials was ineffective. Mentors usually referred themselves to the absence of feedback regarding mentee-related interventions conducted in the community and only once to the unbalanced power between the schools and social services to influence parental involvement, as exemplified in Focus Group 3.

Eloísa: (...) Nowadays, the social worker is more respected by families than teachers. Why? Because they give families MONEY.

Mafalda: Exactly.

Adriana: That's the main problem.

Eloísa: (...) I think... there should be a REAL cooperation between social services and the teacher. Because students have to improve! At least, their behavior has to improve. It has to improve! The grades... I think it's a bit unfair to ask for more (...).

Finally, some mentors referred to Time (3 references) as a factor that negatively influenced SBM. All the discussions included in this subtheme focused on how the mentors considered the program too short to produce significant effects. 
Facilitators of SBM Identified by the Mentors

The Facilitators (30 references) of SBM positive outcomes included the mentors' statements identifying the factors that increased the success of SBM. The most important factor was the Innovative Organization (11 references) promoted by the implementation of an SBM program. Most of the time, the innovative organization made by the mentors was related to the additional care given by school boards in the selection of teachers to work with classes that gathered some of the mentees. In some cases, school boards directly involved the mentors in that process. Only twice did the references coded under this theme depict a diversification of teaching methods to help the mentees to succeed in their learning. The innovative organization related to the selection of teachers to instruct the mentees is described in the following discussion from Focus Group 4:

Luís - (...) the fact that people [mentors] volunteered for the program and the opportunity that we had to choose some of the teachers to work with our mentees (...) Iva already talked about this point.

(Iva nods her head affirmatively.)

Luís - This was very important. It meant that we could influence our colleagues. That was really important (...).

Iva - Our school board also wanted to know our opinion [the opinion of the mentors] about who would be the most appropriate teachers for the classes in which the mentees were enrolled.

In addition, the mentors viewed collaboration with Other Teachers (10 references) at school as an influential factor in the effectiveness of SBM. According to the mentors, the other teachers developed concrete actions to collaborate with the mentoring goals. The mentors described efforts made by other teachers to exchange information to help coordinate teaching and learning strategies within the SBM process. This excerpt from Focus Group 4 illustrates how information was exchanged between mentors and teachers at the beginning of the school year.

Ricardo: In the first meeting I had with teachers, it was explained how... what was my role and what I did and I think they [other teachers] helped to identify certain situations. (...) It was the group of teachers who identified all of those problems, and I think that was very positive.

Isabel: In our school, we also did not have any... any problem with other teachers. On the contrary, the teachers were extremely important to promote the mentees' progresses.

The mentors identified Parental Involvement (7 references) as a factor with a positive influence on mentoring outcomes as well. This positive influence of parents was related to direct parental involvement with mentors and SBM goals. The mentors gathered with parents to assist them in the implementation of solutions to improve their children's achievement or school-related behavior or in improving the definition and consistency of rules at home regarding school issues. The following discussion in Focus Group 1 illustrates how direct contacts with parents and consistency in the definition of rules were part of parental involvement as a SBM facilitator:

Mariana: There's a thing that really contributed to the success of these kids: these parents were our allies.

(Cidália and Rosa nod their heads affirmatively). 
Mariana: Today I have an alliance with them (...) I insisted to talk to both parents so that everyone knew what was going on with the mentee. I also insisted on consequences whenever things went wrong and parents agreed.

Cidália: The more consistent they were, the more results we got.

The mentors seldom viewed the intervention of the Community Stakeholders (2 references) through different social services as relevant to mentoring outcomes.

Mentors referred to the various barriers and facilitators of SBM success in most of the discussions. However, mentors alluded more often to the lack of parental involvement as barrier to SBM success in Focus Group 3 (12 out of 27 references). It was also clear that Innovative Organization was a much more frequent facilitator of SBM identified in Focus Group 4 (7 out of 11 references) compared to the remaining focus groups held with the mentors.

Facilitators of SBM Identified by the Parents

According to Table 5, parents often identified Facilitators (41 references) of SBM, which included the parental statements identifying factors that enabled its success. The most frequently mentioned facilitator was the Mentoring Relationship (16 references). This subtheme involved assertions confirming that SBM success depended on whether the mentoring relationship positively supported the relatedness and competence requirements of the mentees. According to the parents, the satisfaction of relatedness and competence needs of the mentees was often based on SBM frequency and the consistency of contacts. The parents also emphasized that the mentoring relationship was a facilitator of SBM success due to relational features such as mutual interest, closeness and trust. The next example from Focus Group 4 depicts how mutual interest and closeness helped to improve school performance.

Rosa: He really liked his Portuguese Language teacher that was also his mentor. $\mathrm{He}$ had very good grades in Portuguese Language while he was mentored. I started to notice that he loved that teacher. That thing of sending him an e-mail to remind him of tests...he thought it was...

Valéria: Closeness. A kind of closeness with these children.

Rosa: (...) I think she was really interested in him...he liked her and she was always...I'm always telling him to study... and she did the same.

Márcia: My son's mentor was not exactly the same. (...) But when he FINISHED CLASSES, they talked. They talked a lot. And he gave him [the mentee] many ...IDEAS. (...) Once he even told my son: "Look, my family was also poor, and I managed to get my degree. And you are going to make it!" He [the mentor] really supported him [the mentee].

The parents also commented that the effectiveness of SBM depended on positive Communication between Parents and Mentors (13 references). Good communication indicated that the interactions between parents and mentors were frequent, positive, informal and/or based on common perspectives of the schooling of the mentees, as the next example from Focus Group 1 illustrates.

Gracinda: It was not just that thing of talking with a class director when they had time to do it [as it was before mentoring]. They were always available....and the way they communicated with us! 
Avelina: Yes. The way they talked.

Gracinda: The way the mentor talked with us and gave us his or her opinion, and said what they were doing... and all that stuff. We were more informed (...) I even met my kid's classmates. Before, we didn't meet them... we met a few of them. They showed us pictures (...).

(Avelina nods affirmatively).

The parents identified Parental Involvement (6 references) whenever parental actions facilitated the realization of SBM goals. Parents mentioned direct interventions which promoted SBM success such as going to school and discussing solutions with the mentors to promote changes in the school performance or behavior of their children. Parents described indirect interventions to achieve SBM goals, such as setting limits or defining consequences to undesired behaviors. The following discussion from Focus Group 3 depicts how parents tried to define consequences to undesired behaviors after talking to the mentor:

Amélia: For instance, you must have made the same thing I did (points to Luís). I told her (her daughter) that she couldn't show this or that behavior. And then I punished her. For instance, she had to study or I would take her something she enjoyed.

Luís: I did the same. (laughter). I also punished João. If he didn't want to study I told him "Well, you if you don't want to study you don't get to play on the computer." One time, after I talked to the mentor, he was a whole week without going out to see if he changed his behavior at school (...) one week later the mentor called me and asked what had I done to João. And I told her "I only prived him of doing he likes the most." And she said "His behavior changed a lot."

The parents also identified positive influences of the role of Other Teachers (6 references), in terms of their efforts to cooperate with the mentors to fulfill SBM goals. These references were equally divided between adjustments made to teaching methods and adjustments made to the relational style made by the teachers according to the requirements of the mentees, as factors that enhanced the positive effects of SBM.

\section{Barriers to SBM Identified by the Parents}

The Barriers theme (34 references) comprised four subthemes. Communication Parents/ Mentors was the subtheme most often identified (14 references) and included negative appraisals by the parents regarding their communication with mentors, which they described as infrequent, negative, very formal or demanding. All of the references coded under this subtheme, except for two, were remarks of the parents about the meeting conditions which led to negative communication, as depicted in Focus Group 3.

Luís: Sometimes, I had to leave my job to go to school. The mentor said, "You have to come because you are the legal representative" (...) He pressured me a lot. Amélia: But the mentors only receive the parents from 10:30 to 11:30 am. Luís: And sometimes you have those meetings at 6:00 pm or 7:00 pm. Catarina: And in the morning, one of the parents may be working, the other may be at home...

Luís: The schedules make it difficult. Only some parents can go (...). 
The remaining statements included in this subtheme were from the parents acknowledging that they and other parents seldom had the initiative to contact the mentors.

The relationship with Other Teachers (11 references) was the second most mentioned barrier to SBM success. This subtheme incorporated the assertions from parents that recognized that teachers did not adjust their teaching methods and relationships according to the needs of the mentees, as the following account in Focus Group 1 demonstrates.

Gracinda: There was a problem with a teacher (...) She told the students that it was dreadful to teach that class. You can't say something like this. There is no teacher that can say something like this (...) and she was aware that most of her students were mentored. And she knew the goals of mentoring. She shouldn't speak to them [the mentees] like that.

The parents seldom alluded to two additional distinct factors that acted as barriers to SBM success: the Mentee Characteristics (6 references), such as behavior problems, absenteeism or an absence of interest in learning, and Schools (3 references), which included organizational limitations, such as the absence of adult supervision in common spaces or inadequate organization in classes.

Parents referred to the various barriers and facilitators of SBM success in most of the discussions. Nevertheless, parents alluded more frequently to the communication between mentors and parents as a barrier to SBM success in Focus Group 3 (7 out of 14 references).

\section{Discussion}

The aim of this work was to explore the mentor and parental views on the facilitators of and barriers to mentoring effectiveness in a Portuguese SBM program called Metodologia TUTAL. We used the focus group technique to collect data. We organized the discussion of our findings into three subsections: (a) the influence of relational factors on Metodologia TUTAL outcomes; (b) the individual characteristics, implementation factors and SBM success; and (c) the implications, limitations and recommendations.

The Influence of Relational Factors on the Metodologia TUTAL Outcomes

Our main finding was that both the mentors and parents regarded relational factors as the most important determinants of the success of mentoring relationships, which is consistent with other researchers (Deutsch and Spencer 2009; Grossman et al. 2012). Specifically, both mentors and parents discussed the influence of parental involvement, the communication between mentors and parents, the mentors' commitment to the mentoring goals and, more rarely, the role of parallel interventions of community stakeholders on SBM outcomes.

The participants frequently considered parental involvement and the communication between mentors and parents to be an influential factor on the SBM outcomes delivered by Metodologia TUTAL. However, the mentors and parents disagreed on how these two factors affected the mentoring results. Most of the mentors emphasized that parents indirectly influenced SBM goals, because they did not properly support their children learning or had difficulties setting limits regarding school achievement and behavior. Some mentors also mentioned that a few parents underestimated the importance of the school as a place of learning. Similarly, most of the parents identified intransigency from the mentors 
in facilitating meetings, whereas only a few parents acknowledged that they frequently failed to contact the mentors.

The negative views of the mentors and the ambivalent appraisals of the parents regarding parental involvement and the mentors-parents interactions may have resulted from the way in which mentors managed their dual role as mentors and teachers and, concomitantly, from the expectations on the part of the mentors and parents regarding one another's level of commitment to SBM goals. Mentors who emphasized the lack of parental involvement possibly interacted with parents in a formal way, following a bureaucratic or professional approach (Addi-Racah and Ainhoren 2009). The perspectives of these mentors were possibly saturated by narratives regarding how the parents rarely attended school meetings, cared about their children's achievements, supported their children's skills or provided more learning opportunities at home.

The negative opinions of the mentors regarding the parental commitment to the learning needs of their children seem to build on the dominant perspective among formal educators that parental involvement is a unidirectional flow of support from the parents to the school (Hornby and Lafaele 2011). The demands on parental involvement made by formal educators tend to increase when the parents come from lower socioeconomic levels and are less educated (Omer 2011). The teachers usually perceive these more vulnerable parents as being less competent in promoting effective schooling, although the actual frequency of teacher contact and the valorization of schooling do not depend on the wages or educational levels of the parents (Grolnick and Slowiaczek 1994). More importantly, the unrealistic expectations of these mentors that parents would be more cooperative, simply by acknowledging SBM as a caring relationship, likely led them to exaggerate their demands. Consequently, the slightest indication of parental disengagement may have resulted in greater disappointment from the mentors, which was evident in some of the discussions.

However, it is reasonable to assume that, in fact, some of the parents were unavailable to cooperate with the mentors. Some of the parents reported that they were accustomed to negative communication with school representatives, mostly based on their children's shortcomings as students. Several examples in the literature illustrate that negative communications between school representatives and families usually lead to increased parental detachment (González and Jackson 2012; Hornby and Lafaele 2011; Omer 2011). Therefore, parents who reported more communication problems with the mentors may have understood the formal approaches of mentoring to be identical to those made by other teachers in the past. However, it is also reasonable to assume that other parents developed positive expectations regarding the availability of the mentors that, in the end, the mentors did not properly meet. In the discussions, some of the parents emphasized that the mentors were very demanding. This perception possibly led parents to avoid interacting with the mentors, as pressure thwarts parental engagement (Epstein 2001). Ultimately, more formal SBM approaches delivered by mentors who also instruct the mentees may have reproduced or even intensified the tensions and conflicts that dominate negative communications between schools and families (Addi-Racah and Ainhoren 2009; Epstein 2001; Omer 2011).

Only rarely did the mentors refer to the parents as committed partners in helping to fulfill the school requirements of the mentees. Conversely, the parents often acknowledged the direct benefits of SBM relationships for their children. Despite the fact that the mentors held a more thoughtful approach to the mentees' competence and relatedness needs (Ryan and Deci 2000), the parental opinions were contradictory regarding the appropriateness of the communication with the mentors. In addition, parents seldom recognized a greater participation of themselves or of other parents in the schooling of the mentees. It seems 
that even under more favorable communication circumstances and mutual positive perceptions, SBM did not entirely succeed in supporting parental involvement, which could, in turn, improve mentoring effectiveness. This failure reflects the fact that although the parents of vulnerable students may value the direct efforts of the mentors, parental cooperation with school representatives may also require more time (Bæck 2010). More importantly, in our opinion, these findings suggest that officials gave little attention to setting a clear model of cooperation between mentors and parents in Metodologia TUTAL, contrary to the recommendations in the literature (Keller 2005). In fact, the mentors received training on communication and motivational skills to better interact with the parents of the mentees, but this preparation was not supported by a clear and meaningful agenda of parent meetings throughout the school year.

The participants frequently mentioned the role of other teachers as an additional relational factor that also influenced the Metodologia TUTAL outcomes. The mentors regarded teachers as both facilitators of and barriers to SBM relationships. Parents only referred to the teachers as barriers to the SBM aims. Teachers may have facilitated the SBM goals because the efforts of the mentors in this program to assist the learning needs of their mentees may have been more recurrent, or at least more evident, than the identical efforts of the mentors in other programs. Multiple lines of evidence support this reasoning; for example, other SBM programs delivered by volunteer mentors rarely provide academic tasks during mentor-mentee meetings (Herrera et al. 2007). By the contrary, other findings pertaining to Metodologia TUTAL sustain that learning issues and activities frequently dominated the one-on-one mentoring meetings in this SBM program (Simões and Alarcão, submitted). Other teachers may have also been more inclined to cooperate because the SBM sessions in this program did not involve removing the mentees from their classes. In SBM programs that required removing the mentees from classes to meet with their mentor, $39 \%$ of the teachers did not allow students to attend SBM meetings on a regular basis, and $28 \%$ of the teachers did not agree with the mentoring goals (Schwartz et al. 2012). Additionally, some of the schools that implemented the program associated certain organizational innovations with the implementation of SBM, such as taking additional care in the selection of teachers to instruct the mentees. This unintended feature of the program implementation may have facilitated cooperation between mentors and teachers and the completion of SBM goals.

On the contrary, sometimes teachers may have acted as a barrier to SBM purposes mostly because, similarly to parents, the program overlooked teacher involvement. Officials informed the teachers of the SBM purposes by the start of the school year, but they failed to schedule follow-up meetings to facilitate an on-going evaluation of the program. In addition, the parental opinions that the teachers were often an obstacle to SBM goals may be regarded as a true lack of teacher involvement with the SBM aims or merely as an expression of the typical tensions between schools and families (Epstein 2001; Omer 2011).

The Individual Characteristics of the Mentees and the Implementation Factors

According to our findings, the individual characteristics of the mentee had only a marginal influence on SBM outcomes. However, other studies depicted the profiles of the mentees as a determinant source of influence on SBM effectiveness. Indeed, previous reports have shown that individual variables, such as the gender and age of the mentees (Karcher 2008) and the level of individual, environmental (DuBois et al. 2011) and relational risk (Schwartz et al. 2011), moderate the effects of SBM. 
At a first glance, our findings seem to be inconsistent with other studies in the SBM area. However, we consider our results to reflect the incorporation of good SBM practices in Metodologia TUTAL. The mentors delivered mentoring at the schools where they taught (DuBois et al. 2002), the mentoring continued for a longer period (9 months) than the average 5-month duration of SBM relationships (Grossman et al. 2012), and the mentors were trained and supervised (Komosa-Hawkins 2009). Altogether, these facts might have helped SBM to draw connections between formal and informal types of authority and to increase the endorsement of the school norms by the mentees (Goldner and Mayseless 2008). In addition, the SBM delivered under these conditions likely contributed to buffer the practical drawbacks of SBM interventions, such as the organization of mentor-mentee matching or the definition of SBM schedules and activities, which are strongly associated with a positive management of the mentees' characteristics (Chan and Ho 2008; Karcher 2008). The trivial influence of the individual variables of the mentees in promoting the success of SBM relationships in Metodologia TUTAL, according to the perceptions of the mentors and parents, was also possibly linked to the combination of group and one-on-one mentoring activities. In our opinion, this option facilitated a smoother transition between the usual social context of the school (class) and the most common framework of mentoring (one-on-one meetings), preventing a negative labeling of SBM as a relationship prescribed to certain students, due to their history of failure.

Implications, Limitations and Recommendations

Our work has two major implications. First, our study supports the idea that teachers may effectively deliver SBM, as long as programs and agencies give further attention to the complex network of relationships among the most significant adults in the lives of the mentees. Abundant and rewarding interactions between mentors and parents, consistent commitment of teachers to SBM goals or a more fruitful cooperation with the community stakeholders is achievable if programs create better communication channels between mentors, parents, teachers and social services officials and clarify the roles, responsibilities and expectations of each group. More specific training of the mentors regarding this issue, the definition of an on-going schedule of meetings or the promotion of culturally relevant informal activities that involve the parents and teachers of the mentees, are all additional suggestions that may foster this paramount aim as well (González and Jackson 2012).

Second, teachers in the role of mentors may have helped to better contextualize some of the implementation stages of the program, such as the matching process, the meeting schedules and the combination of the usual school interactions in the group with the oneon-one interactions. These program features may help to further explain the insignificant contribution of the individual characteristics of the mentees to SBM outcomes. However, our interpretation requires new research efforts that compare the effects of programs delivered in similar conditions to those of Metodologia TUTAL to other programs delivered by mentors who do not have a background in educational roles.

Our work has some limitations as well, which are related to individual, interactional and situational factors that determine the course of focus groups. Individual factors associated with self-selection bias may have influenced our findings, as some of the invited mentors and parents were not available to collaborate on the study. The interactional factors, in terms of the organization of the focus groups, may have affected the results as well. We deliberately manipulated the composition of the groups to balance its homogeneity and heterogeneity. For instance, we managed heterogeneity by including mentors and parents associated with at least two different schools in each of the discussions in order to prevent 
familiarity between the participants and social conformism (Vicsek 2010). Although each of the emergent subthemes generally received equal emphasis across the various focus groups, a small number of exceptions possibly stemmed from how the groups were organized. For example, most of the references made by the mentors to the innovations promoted by SBM in schools came from Focus Group 4. These mentors may have been more likely to discuss facilitators of or barriers to learning and school performance compared to other factors, because most of them were more experienced as teachers.

Among the situational factors, the context in which the discussions took place may also have been influential. Two of the discussions with the mentors took place at one of the schools where the program was implemented; the remaining discussions were held at the non-governmental organization responsible for managing the program. This may also have affected the results, because the contexts can determine the cognitive and emotional activation of the experiences of the participants (Wengraf 2001).

The data collection procedure also presents some drawbacks. The focus group technique is a cross-sectional and retrospective technique by nature (Krueger and Casey 2008). The use of other data collection techniques, such as the interview; the involvement of other informers, including the mentees or the use of more sophisticated study designs and data analysis techniques, such as hierarchical linear modeling, would improve future studies. These methodological options could enable comparisons of the concurrent influence of relational, individual and implementation factors that determine SBM outcomes.

\section{Conclusions}

The participants considered that the relationships established between mentors and parents, teachers and, more rarely, social services officials frequently influenced SBM delivered in Metodologia TUTAL. Conversely, they seldom regarded the characteristics of the mentees as an important influence on mentoring outcomes. Our findings suggest that SBM delivered by teachers may help to tackle certain practical limitations of this sort of intervention. However, the overlap of mentoring and teaching roles in SBM may also necessitate additional care regarding the definition of the purposeful interactions of mentors with the other significant adults in the lives of the mentees.

Acknowledgments We would like to thank the participants. We would also like to thank Filipe Fernandes, Melanie Petiz and Pedro Pereira for their cooperation in the inter-coders agreement process and the reviewers for their valuable contributions. This work was supported by a grant of the Foundation for Science and Technology (SRFH/BD/60823/2009).

\section{References}

Addi-Racah, A., \& Ainhoren, R. (2009). School governance and teachers' attitudes to parents' involvement in schools. Teaching and Teacher Education, 25(6), 805-813.

Bæck, U. D. (2010). Parental involvement practices in formalized home-school cooperation. Scandinavian Journal of Educational Research, 54(6), 549-563.

Bardin, L. (2004). Análise de conteúdo [Content analysis] (p. 70). Lisboa: Edições.

Bryman, A. (2006). Integrating quantitative and qualitative research: How is it done? Qualitative Research, $6(1), 97-113$.

Chan, C. S., \& Ho, W. (2008). An ecological framework for evaluating relationship-functional aspects of youth mentoring. Journal of Applied Social Psychology, 38(4), 837-867. 
Chan, C. S., Rhodes, J. E., Howard, W. J., Lowe, S. R., Schwartz, S. E. O., \& Herrera, C. (2013). Pathways of influence in school-based mentoring: The mediating role of parent and teacher relationships. Journal of School Psychology, 51(1), 129-142.

Deutsch, N. L., \& Spencer, N. (2009). Capturing the magic: Assessing the quality of youth mentoring relationships. New Directions for Youth Development, 121, 47-70.

DuBois, D. L., Holloway, B. E., Valentine, J. C., \& Cooper, H. (2002). Effectiveness of mentoring programs for youth: A meta-analytic review. American Journal of Community Psychology, 30(2), 157-197.

DuBois, D. L., Portillo, N., Rhodes, J. E., Silverthorn, N., \& Valentine, J. C. (2011). How effective are mentoring programs for youth? A systematic assessment of the evidence. Psychological Science in the Public Interest, 12(2), 57-91.

Eagly, A. H., \& Chaiken, S. (1993). The psychology of attitudes. London: Harcourt Brace Jovanovich College.

Epstein, J. L. (2001). School, family and community partnerships. Boulder, CO: Westview Press.

Goldner, L., \& Mayseless, O. (2008). Juggling the roles of parents, therapists, friends and teachers: A working model for an integrative conception of mentoring. Mentoring \& Tutoring: Partnership in Learning, 16(4), 412-428.

González, R. L., \& Jackson, C. L. (2012). Engaging with parents: The relationship between school engagement efforts, social class, and learning. School Effectiveness and School Improvement, 1(1), $1-20$.

Grolnick, W. S., \& Slowiaczek, M. L. (1994). Parents' involvement in children's schooling: A multidimensional conceptualization and motivational model. Child Development, 65(1), 237-252.

Grossman, J. B., Chan, C. S., Schwartz, S. E. O., \& Rhodes, J. E. (2012). The test of time in SBM: The role of relationship duration and re-matching on academic outcomes. American Journal of Community Psychology, 49(1), 43-54.

Herrera, C., Grossman, J. B., Kauh, T. J., Feldman, A. F., McMaken, J., \& Jucovy, L. Z. (2007). Making a difference in schools: The Big Brothers Big Sisters school-based mentoring impact study. Philadelphia, PA: Public/Private Ventures.

Herrera, C., Grossman, J. B., Kauh, T. J., \& McMaken, J. (2011). Mentoring in schools: An impact study of Big Brother Big Sisters school-based mentoring. Child Development, 82(1), 346-361.

Hornby, G., \& Lafaele, R. (2011). Barriers to parental involvement in education: An exploratory model. Educational Review, 63(1), 37-52.

Karcher, M. J. (2008). The study of mentoring in the learning environment (SMILE). A randomized evaluation of the effectiveness of SBM. Prevention Science, 9(2), 99-113.

Karcher, M. J., Nakkula, M. J., \& Harris, J. (2005). Developmental mentoring match characteristics: Correspondence between mentors' and mentees' assessments of relationship quality. The Journal of Primary Prevention, 26(2), 93-110.

Keller, T. E. (2005). A systemic model of youth mentoring intervention. The Journal of Primary Prevention, 26(2), 169-188.

Komosa-Hawkins, K. (2009). Best practices in school-based mentoring for adolescents. Child \& Youth Services, 31, 121-137.

Krueger, R. A., \& Casey, M. A. (2008). Focus Groups: A practical guide for applied research. Thousand Oaks, CA: SAGE Publications.

Miller, A. (2007). Best practices for formal youth mentoring. In T. D. Allen \& L. T. Eby (Eds.), The Blackwell handbook of mentoring: A multiple perspectives approach (pp. 307-324). Malden, MA: Blackwell Publishing.

Omer, H. (2011). The new authority: Family, school and community. New York: Cambridge University Press.

Rhodes, J. E. (2002). Stand by me: The risks and rewards of mentoring today's youth. Cambridge, MA: Harvard University Press.

Russell, L. (2007). Mentoring is not for you! Mentee voices on managing the mentoring experience. Improving Schools, 10(1), 41-52.

Ryan, R. M., \& Deci, E. L. (2000). Intrinsic and extrinsic motivation: Classic definitions and new directions. Contemporary Educational Psychology, 25(1), 54-67.

Schwartz, S. E. O., Rhodes, J. E., Chan, E. S., \& Herrera, C. (2011). The impact of school-based mentoring on youths with different relational profiles. Developmental Psychology, 47(2), 450-462.

Schwartz, S. E. O., Rhodes, J. E., \& Herrera, C. (2012). The influence of meeting time on academic outcomes in school-based mentoring. Children and Youth Services Review, 34(12), 2319-2326.

Simões, F., \& Alarcão, M. The structure and process of social support in school-based mentoring from a self-determination theory perspective. The Journal of Social Psychology of Education (submitted). 
Spencer, R. (2006). Understanding the mentoring process between adolescents and adults. Youth \& Society, 37(3), 287-315.

Spencer, R., Basualdo-Delmonico, A., \& Lewis, T. O. (2011). Working to make it work: The role of parents in the youth mentoring process. Journal of Community Psychology, 39(1), 51-59.

Vicsek, L. (2010). Issues in the analysis of focus groups: Generalisability, quantifiability, treatment of context and quotations. Qualitative Report, 15(1), 122-141.

Wengraf, T. (2001). Qualitative research interviewing: Biographic narrative and semi-structured methods. London: Sage Publications.

Wheeler, M. E., Keller, T. E., \& DuBois, D. L. (2010). Review of three randomized trials of school-based mentoring: Making sense of mixed findings. Social Policy Report, 24(3), 1-21. 